\title{
NASAL SPLINTS AND NOSE GUARDS
}

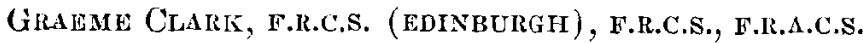 \\ Department of Physiology, University of Sydney
}

Nasal FRACTuRes are common, and although their surgical treatment is standardized, there is disagreement about their splintage and postoperative management. A variety of nasal splints are at present in use, and some can be seen in Figure 1. Small splints of aluminium or dental impression compound, which can be moulded to the nose, are available. More commonly a plaster splint is applied, and this is fixed in place with adhesive strapping or tapes around the head. The plaster may be cut so

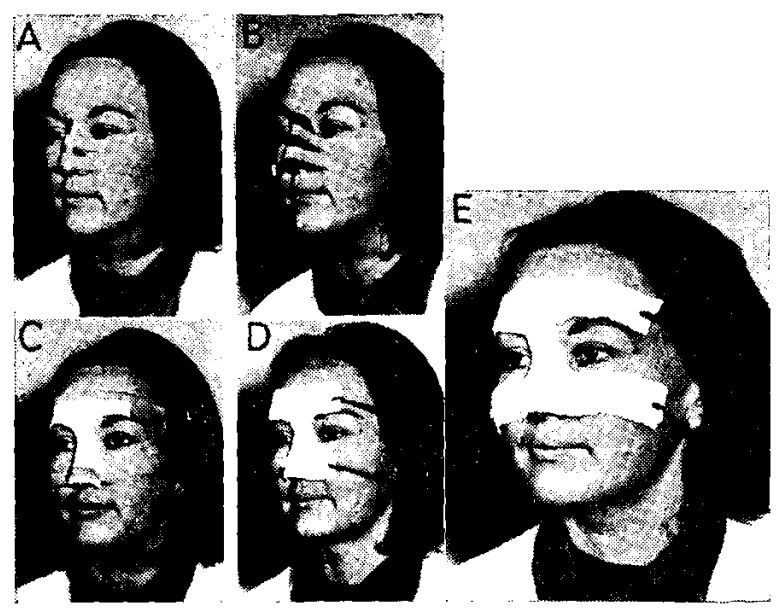

Figure 1: Nasal splints. A, aluminium; B, dental impression compound: $C$, plaster with a forehead flange: $D$, plaster With forehead and maxillary flanges; $E$, plaster with flanges extending to the lateral aspect of the skull

that it has a broad area for attachment to the forehead (Figure $1 \mathrm{C}$ ) or broad flanges for resting on the maxilla to provide further support (Figure $1 \mathrm{D}$ ). In the latter case, the plaster is usually fixed in place by connecting it to tapes which are tied behind the head.

In no case should a splint be applied in the hope that it can exert pressure on and compensate for an incompletely reduced fracture. Satisfactory postoperative results will be obtained only if reduction is complete at the time of the operation. Therefore the main function of splints for nasal fractures without loss of support is to prevent further injuries displacing the bones during healing.

\section{SPLINTS FOR NASAL FRACTURES WITHOUT LOSS OF SUPPORT}

In a recent study by the writer (Clark and Wallace, 1968), in which the strains in different parts of the nasal and septal bones were measured in response to forces applied from different directions, it was noted that a lateral force to the dorsum of the nose caused more strain in the nasal bones than a frontal one. A lateral glancing blow to the nose is more common than a direct frontal one, and nasal splints should protect the nose from this type of injury.
The small aluminium and impression compound splints (Figures $1 \mathrm{~A}$ and $1 \mathrm{~B}$ ) will not protect the nose from frontal or lateral forces, as they only cover the nose and are fixed to the face with adhesive strapping. The plaster with a broad area for attachment to the forehead (Figure 1 C) provides some protection from frontal forces, but will tend to rotate around a horizontal axis through the lower border of the forehead attachment. The plaster with maxillary flanges (Figure $1 \mathrm{D}$ ) is the only one which will provide complete protection from a frontal force. This plaster, however, will not give complete protection from a lateral blow, as a torque will develop, and the attachment of the plaster to the skin through the adhesive strapping will be the only resisting force. It is suggested that if there is any possibility of the patient receiving a blow to the nose, the plaster splint should have broad

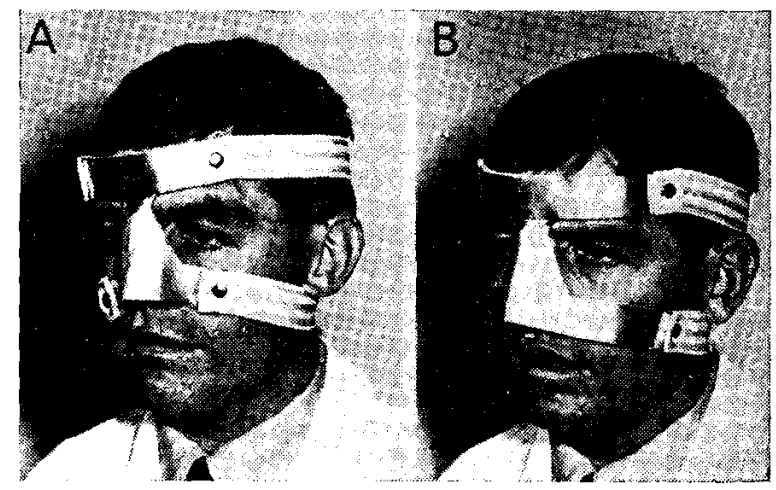

Ficure 2: Nose guards. A, standard design; B, modified design with flanges extending to the lateral aspect of the skull and face.

attachments, with the forehead and maxillary flanges extending around the lateral aspects of the skull, as shown in Figure $1 \mathrm{E}$. In this way the nose will be protected from a substantial lateral blow.

\section{SPLINTS FOR NASAL FRACTURES WITH LOSS OF SUPPORT}

A fracture of the nose may lead to collapse of the dol'sum due to loss of support. This is likely to occur if an area of the septum called the "cantilever" (Clark, 1967) has been weakened. In such a case, nasal splints should provide active support to the nose until the bones have united in their corrected position. The nose may be splinted by intranasal packing, some form of suspension through an attachment to a plaster head cap, or transnasal wiring of intranasal splints sutured on either side of the septum. More recently, the use of an intraseptal splint of heterogenous cortical bone ("Boplant"), in the treatment of a saddle nose due to injury, has been described (Clark. 1968). 


\section{NOSE GUARDS}

It is my clinical impression that people who fracture their noses are predisposed to a recurrence of the injury, and $I$ advise those participating in active sport to use a nose guard. The standard form of nose guard avallable can be seen in Figure $2 \mathrm{~A}$. This provides good protection from a frontal injury but a lateral blow can displace the nose, and therefore a nose guard has been designed so that the frontal and maxillary flanges extend around the lateral aspects of the face for greater protection (Figure $2 \mathrm{~B}$ ).

\section{SUMMARY}

The advantages of different splints for nasal fractures have been discussed. Small splints which just cover the nose do nat provide much protection against frontal and lateral forces. Plaster splints with frontal and maxillary flanges give adequate support against frontal injuries, but only provide adequate protection against forces from the lateral side when the flanges are extended around the side of the skull and face.

A standard nose guard also gives adequate support against frontal blows but again only provides adequate protection against blows from the lateral side when the flanges are extended around the side of the skull and face.

\section{- REFERENCES}

Clark, G. M. (1967), "The Role of the Nasal Septum in OneStage Rhinoplasty", Arch. Otolaryng., 85: 418.

Clark, G. M. (1968), "Septal Transplant for a Sadule Nose Due to Injury", Arch. Otolaryng., 88: 113.

Clark, G. M., and Wallace, C. S. (1968), "A Mathematical and Mechanical Analysis of Nasal Support", submitted for publication. 


\section{University Library}

\section{- M M I E E R VA A gateway to Melbourne's research publications}

Minerva Access is the Institutional Repository of The University of Melbourne

Author/s:

Clark, Graeme M.

Title:

Nasal splints and nose guards

Date:

1969

Citation:

Clark, G. M. (1969). Nasal splints and nose guards. Medical Journal of Australia, March, 1 , 573-574.

Persistent Link:

http://hdl.handle.net/11343/27110 